\title{
The Effects of Psychological Distance on Sport Consumers' Purchase Intentions
}

\author{
Geumchan Hwang \\ Department of Human Performance and Health Education, Western Michigan University \\ 1903 W Michigan Ave, Kalamazoo, MI 49008
}

\begin{abstract}
Sport consumers purchase products or services online based on several factors. In particular, psychological distance is a significant factor that affects decision making, and it is important to understand how multiple dimensions of psychological distance influence sport consumers' purchase intentions. Therefore, the purpose of the study was to examine the different impact of social, temporal, and spatial distance on sport consumers' purchase intentions online. An online experimental survey was employed and 103 samples were collected from college students in Midwest area. Analysis of variance was conducted and the findings showed different effects of psychological distance on sport consumers' purchase intentions online between social distance and temporal distance, and social distance and spatial distance. This study provides sport marketer with practical information about online marketing strategies.
\end{abstract}

Keywords: social, temporal, spatial, psychological distance, sport consumers, purchase intentions

DOI: $10.7176 / \mathrm{JMCR} / 80-03$

Publication date:July $31^{\text {st }} 2021$

\section{Introduction}

With the growth of the e-commerce market, purchasing a product via online websites has become popular nowadays (Albinsson, Burman, Das, 2010). Many researchers have studied what factors affect a consumer's purchasing decisions, and found that a consumer's inherent construal level affects a consumer's decision making (Albinsson et al., 2010; Kim \& John, 2008). According to Construal Level Theory (CLT), people tend to interpret an event in a more abstract, goal oriented and general way when they are psychologically distant, whereas they interpret an event more concretely when the psychological distance is close (Humphreys, Isaac, \& Wang, 2020; Liberman \& Fo r̈ster, 2009; Liberman \& Trope, 2008; Liberman, Trope, \& Stephan, 2007; Liu, Zhang, Huang, Zhang, \& Zhao, 2020; Trope \& Liberman, 2003).

Previous CLT studies examined the impact of psychological distance on people's thoughts and behaviors (Liu et al., 2020; Trope, Liberman, \& Wakslak, 2007) focusing on temporal distance (Liberman, Sagristano, \& Trope, 2002), spatial distance (Fujita, Henderson, Eng, Trope, \& Liberman, 2006), and social distance (Stephan, Liberman, \& Trope, 2010). However, previous studies ignored several dimensions of psychological distances (i.e., temporal, spatial, and social distance) simultaneously affect people's thoughts and behaviors (Kim, Zhang, $\& \mathrm{Li}, 2008)$. For example, sport consumers make purchasing decisions online based on diverse impact of psychological distance, such as social distance (e.g., close friends/customer reviews), temporal distance (e.g., previous experience/current experience), and spatial distance (e.g., domestic manufacturing product/outsource manufacturing product).

Despite many CLT studies (Albinsson et al., 2010; Kim \& John, 2008; Liberman \& Fo r̈ster, 2009; Liberman \& Trope, 2008; Liberman, et al., 2007; Trope \& Liberman, 2003), little is known of how psychological distances (i.e., social, temporal, and spatial distance) differently affect sport consumers' purchasing decisions online. Therefore, this study aims to examine the different impact of social, temporal, and spatial distance on sport consumers' purchasing intentions online.

\section{Literature Review}

Researchers (Ahuja, Gupta, \& Raman, 2003; Albinsson et al., 2010; Humphreys et al., 2020; Liu et al., 2020; Nan, 2007; Williams \& Bargh, 2008) examined how construal level influences consumers' purchasing decisions. For example, Albinsson et al. (2010) studied effects of construal level on consumers' purchasing intention online and found consumers evaluated online products differently based on their inherent construal level. In a similar vein, Nan (2007) examined the influence of social distance on individuals' responses to persuasive messages and found the impact of persuasive message becomes stronger when people consider the socially distant information (e.g., others) compared to socially close information (e.g., selves). Williams and Bargh (2008) examined the impact of spatial distance and found it differently affects consumers' thoughts and feelings.

Three dimensions of the psychological distance (i.e., social, temporal, and spatial distance) have been important themes that influence consumers' thoughts, feelings, and behaviors (Liberman, Trope, \& Wakslak, 2007). Social distance refers to the degree to which people feel separated from others and the temporal distance is related to saving or investing for the future or reflecting past behaviors. Spatial distance means geographical 
distance (i.e., close or far distance) and it affects consumers' thoughts (Liberman et al., 2007). Initial concerns of CLT studies emphasized how a single dimension of psychological distance affects a consumer behavior but attention has now shifted toward how multiple dimensions of psychological distance interact with each other and how the interaction affects consumers' thoughts and behaviors.

Liberman et al. (2007) focused on interaction between dimensions of psychological distance, and demonstrated that impact of distance on one dimension can be reduced when more than two different dimensions are combined. Kim et al. (2008) have studied that how consumers evaluate products when two dimensions of psychological distance (e.g., temporal distance and social distance) are jointly considered and found that consumer evaluation is more affected by values related to low construal level when two distance dimensions are proximal than when both dimensions are distal.

\section{Method}

This study employed an online experimental design, using three fictitious scenarios of social distance (close / far), temporal distance (close / far), and spatial distance (close / far). Samples were recruited from college students in the Midwest area. College students were selected because they are active consumers who purchase sport products online. A survey email was sent out to college students and total 103 samples (male: 56/ female: 47) were collected.

For the social distance scenario, information about the online products from a close friend's comments and an anonymous reviewer's comments on the website were given. For the close friend's comments, participants were asked to imagine that one of their best friends gave the participants information about the online product via text messages. For the anonymous reviewer's comments, a fictitious reviewer's comment was shown on the computer screen. For the temporal distance scenario, customer reviews left three year ago and an hour ago were used. Participants were asked to imagine that they read two customer reviews left three years ago and an hour ago. For the spatial distance scenario, two fictitious customer reviews left in U.S. and out of U.S. were used. Participants were asked to imagine they read customer reviews left in U.S. and Asia countries.

First of all, fictitious information about a fitness watch was given and participants were asked to imagine that they are going to purchase the fitness watch online. Each participant was asked to answer their purchase intentions toward after reading fictitious information about customer reviews. Regarding the customer reviews, one positive review and one negative review about the fitness watch were randomly given. These positive or negative reviews were created based on review pages from online shopping sites. For the manipulation check, participants were asked to answer whether a friend is a psychologically closer person than the reviewer $(M=$ 5.04, $S D=1.30$ ), whether the message reviewed an hour ago is temporally closer to present time than the message reviewed three years ago $(M=4.79, S D=1.31)$, and whether the message reviewed in U.S. is spatially closer than the message reviewed out of U.S $(M=4.91, S D=1.18)$. The manipulation check was successfully ensured based on the results of descriptive analysis.

To measure the participant's purchase intention, three items were modified from Becker-Olsen, Cudmore, and Hill (2006). Items included "I will consider purchasing the product," "I am likely to purchase the product," and "I am probable to purchase the product. All items were measured based on 7-point Likert scale $(1=$ Strongly Disagree / 7 = Strongly Agree). Analysis of variance (ANOVA) was used to examine different impact of psychological distance on purchase intentions among social, temporal, and spatial distance.

\section{Results}

101 samples (male: 54 / female 47) were used for data analysis after deleting incomplete data. The average age of participants was $23.53(S D=4.83)$ and the effect of social distance on online purchase intentions was the highest $(M=4.21, S D=1.66)$ and followed by spatial distance $(M=3.36, S D=1.50)$ and temporal distance $(M$ $=3.11, S D=1.50)$. A one-way ANOVA was conducted to test the mean difference of online purchase intentions among three dimensions of psychological distance (i.e., social, temporal, and spatial distance). Results showed a significant mean difference of online purchase intentions among three dimensions of psychological distance $(F$ $(2,300)=13.90 ; p<.05)$. Post hoc tests were conducted using Tukey's range test to compare specific mean differences of online purchase intentions among three dimensions of psychological distance. Post hoc tests revealed significant mean differences of online purchase intentions between social distance $(M=4.21, S D=1.66)$ and temporal distance $(M=3.11, S D=1.50)$, and social distance $(M=4.21, S D=1.66)$ and spatial distance $(M=$ $3.36, S D=1.50)$ at the alpha level of .05 . The difference between temporal distance and spatial distance was not significant.

\section{Discussion}

This study aimed to examine different effects of psychological distance (i.e., social, temporal, and spatial distance) on consumers' purchase intentions online and found different effects of psychological distance between social distance and temporal distance, and social distance and spatial distance. Previous CLT studies showed 
people interpret an event depending on the psychological distance and it influence consumers' purchasing decisions (Ahuja et al., 2003; Albinsson et al., 2010; Nan, 2007; Williams \& Bargh, 2008). In the same context, this study revealed three dimensions of psychological distance (i.e., social, temporal, and spatial distance) differently affected consumers' purchasing intentions online. Therefore, this study is in line with the findings of the previous studies. In addition, the findings of the study advance the understanding of multiple effects of psychological distance on consumers' purchasing intentions. This study examined different effects of social, temporal, and spatial distance on purchasing intentions while previous CLT studies focused only on examining single effect of the psychological distance. Prior to this study, there was a lack of understanding of interaction effects among social, temporal, and spatial distance on consumers' purchasing intentions. Thus, the findings of the study contribute to better understanding of psychological distance.

This study provides marketer with practical information about online marketing strategies. First, marketers should ensure the reliability of online reviews. Regarding the effect of social distance, consumers tend to compare information source received from family or friends to online reviews. This means unreliable reviews negatively affect consumers' purchasing intentions and it might lead to deteriorate the reputation of the shopping site. Therefore, marketers should provide consumers with credible sources about sport products online. Regarding the effect of temporal and spatial distance, marketers should provide transparent information about time and location of the reviews so consumers receive unbiased information about the sport products. For example, sport marketers should reveal accurate information about where and when the message was reviewed. This will help sport consumers to make a right decision and ultimately enhance the reputation of the website.

This study has several limitations. First, there was a generalizability issue. Specifically, only one sport product was tested in this study. This means the findings of the study might be different depending on sport products used in the study. Second, there is no clear explanation about the difference between close and distant psychological distance, and to what extent the difference of psychological distance meaningfully affects the results of study. Finally, this study did not consider other possible variables that might affect results of the study, such as contents of the reviews, attitudes toward sport products, individual difference, gender difference, and so on.

Therefore, future research should focus more on examining factors that moderate the influence of psychological distance on consumers' purchasing intentions. Additionally, future research should design more precise and feasible scenarios to ensure validity of the study.

\section{References}

Ahuja, M., Gupta, B., \& Raman, P. (2003). An empirical investigation of online consumer purchasing behavior. Communications of the ACM, 46, 145-151.

Albinsson, P. A., Burman, B., \& Das, N. (2010). Price surcharge and the effects of construal level. Journal of Applied Business and Economics, 11, 56-69.

Becker-Olsen, K. L., Cudmore, A. B., \& Hill, R. P. (2006). The impact of perceived corporate social responsibility on consumer behavior. Journal of Business Research, 59, 46-53.

Fujita, K., Henderson, M. D., Eng, J., Trope, Y., \& Liberman, N. (2006). Spatial distance and mental construal of social events. Psychological Science, 17(4), 278-282.

Humphreys, A., Isaac, M. S., \& Wang, R. J. H. (2020). Construal matching in online search: applying text analysis to illuminate the consumer decision journey. Journal of Marketing Research, 0022243720940693.

Kim, H., \& John, D. R. (2008). Consumer response to brand extensions: Construal level as a moderator of the importance of perceived fit. Journal of consumer psychology, 18(2), 116-126.

Kim, K., Zhang, M., \& Li, X. (2008). Effects of temporal and social distance on consumer evaluations. Journal of Consumer Research, 35, 706-713.

Liberman, N. \& Fo rister, J. (2009). The effect of psychological distance on perceptual level of construal. Cognitive Science, 33, 1330-1341.

Liberman, N. \& Trope, Y. (1998). The role of feasibility and desirability considerations in near and distant future decisions: A test of temporal construal theory. Journal of Personality and Social Psychology, 75, 5-18.

Liberman, N., Sagristano, M., \& Trope, Y. (2002). The effect of temporal distance on level of construal. Journal of Experimental Social Psychology, 40, 586-598.

Liberman, N., Trope, Y., \& Stephan, E. (2007). Psychological distance. In A. W. Kruglanski \& E. T. Higgins (Eds.), Social psychology: Handbook of basic principles. New York, NY: Guilford Press.

Liberman, N., Trope, Y., \& Wakslak, C. (2007). Construal Level Theory and consumer behavior. Journal of Consumer Psychology, 17, 113-117.

Liu, Q., Zhang, X., Huang, S., Zhang, L., \& Zhao, Y. (2020). Exploring consumers' buying behavior in a large online promotion activity: The role of psychological distance and involvement. Journal of theoretical and applied electronic commerce research, 15(1), 66-80.

Nan, X. (2007). Social distance, framing, and judgment: A construal level perspective. Human Communication 
Research, 33, 489-514.

Stephan, E., Liberman, N., \& Trope, Y. (2010). Politeness and social distance: A construal level perspective. Journal of Personality and Social Psychology, 98, 268-280.

Trope, Y., \& Liberman, N. (2003). Temporal construal. Psychological Review, 110, 403-421.

Trope, Y., Liberman, N., \& Wakslak, C. (2007). Construal level and psychological distance: Effects on representation, prediction, evaluation, and behavior. Journal of Consumer Psychology, 17, 83-95.

Williams, L. E., \& Bargh, J. A. (2008). Keeping one's distance: The influence of spatial distance cues on affect and evaluation. Psychological Science, 19, 302-308. 